\title{
Concealed Coronoid Hydrocarbons with Enhanced Antiaromatic Circuit Contributions as Models for Schottky Defects in Graphenes
}

\author{
Jerry Ray Dias* \\ Department of Chemistry, University of Missouri, Kansas City, MO 64110-2499, USA

\begin{abstract}
Coronoids with holes shaped like an odd carbon benzenoid have antiaromatic holes and antiaromatic conjugated circuits. Another class of concealed diradical coronoids has been identified. They are Hückel molecular orbital diradicals $(\mathrm{HOMO}=\mathrm{LUMO}=0$, each with a single electron occupancy) that have VB (valence-bond) structures $(\boldsymbol{K} \neq 0)$. This new class of concealed diradical coronoids have more enhanced antiaromatic contributions. The smallest holes in graphenes are spin polarized and have antiaromatic characteristics.
\end{abstract}

Keywords: Antiaromaticity, concealed diradicals, coronoid hydrocarbons, Schottky defects, antimolecule, graphenes.

\section{INTRODUCTION}

The number of Kekulé resonance structures $(\boldsymbol{K})$ and isomers of coronoid hydrocarbons have been enumerated by Cyvin, Gutman, and coworkers [1]. Coronoid hydrocarbons with holes shaped like an odd carbon benzenoid, like coronphene $\left(\mathrm{C}_{36} \mathrm{H}_{18}\right)$ which has phenalenyl-like hole, have antiaromatic holes and antiaromatic circuit ( $4 n$ conjugated circuits) contributions [2]. Graphene defects having holes that are shaped like benzenoids occur without distorting the planar layer whereas defects with holes that are shaped like other ring-size motifs result in distortion of graphene layer. In a prior paper, [2] we examined the latter type of defect. Herein, we will examine the former type of defect in model coronoid systems.

\section{Antiaromaticity}

The concept of antiaromaticity was introduced by Ronald Breslow [3]. In regard to the energy of a molecular system, antiaromaticity is a more destabilizing phenomenon than aromaticity is stabilizing. This can be seen by comparing the resonance energies per electron for benzene and cyclobutadiene, respectively, by various methods: conjugated circuit theory gives $0.140 \mathrm{eV} / \mathrm{electron}$ and $-0.163 \mathrm{eV} /$ electron [4], topological resonance energy (TRE) gives $0.0455 \beta /$ electron and $-0.306 \beta /$ electron [5], and the Hess and Schaad resonance energy per electron (REPE) gives $0.092 \mathrm{eV}(0.065 \beta)$ and $-0.381 \mathrm{eV}(-0.268 \beta)[6]$. Higher $a b$ initio calculations by von Rague Schleyer and coworkers [7] give aromatic stabilization/antiaromatic destabilization energies of 29.0 $\mathrm{Kcal} / \mathrm{mol}$ (4.83 kcal/mol per carbon) for benzene and -31.4 $\mathrm{kcal} / \mathrm{mol}(-7.85 \mathrm{kcal} / \mathrm{mol}$ per carbon) for bond alternant cyclobutadiene. Previously we have argued that in general antiaromatic molecules have $4 n$ conjugated circuits, are HMO diradicals, but are VB nonradicals [8]. This theme is continued herein.

\footnotetext{
*Address correspondence to this author at the Department of Chemistry, University of Missouri, Kansas City, MO 64110-2499, USA; Tel: (816) 235-2284; Fax: (816)235-5502; E-mail: diasj@umkc.edu
}

\section{RESULTS AND DISCUSSION}

\section{Antiaromatic Holes}

Aihara showed that [9]coronaphene is "marginally antisuperaromatic" which means that there is extra destabilization due to the $4 n$ macrocyclic conjugation contribution, although the entire $\pi$ system is highly aromatic [9]. In the case of [9]coronaphene $\left(\mathrm{C}_{36} \mathrm{H}_{18}\right)$, the most important antiaromatic macrocyclic conjugation contribution out of 512 antiaromatic macrocyclic circuits is the $\mathrm{C} 12$ inner conjugated circuit. We refer to the inner $\mathrm{C} 12$ circuit as an antiaromatic hole [2].

Such an antiaromatic hole has unique attributes in graphenes. Graphenes are well-defined, nanosized polycyclic aromatic hydrocarbons having potential uses in the fabrication organic electronic devices [10]. Removal of a single carbon atom from a graphite system generates a point defect that is a one-atom hole (called a Schottky defect) [11]. Using Aihara's topological superaromatic stabilization energy ( $t$ SSE) index, it was shown that coronoid related systems that were HMO (Hückel MO) diradicals but VB (valence-bond) nonradicals (Kekuléan systems) displayed relatively more enhanced macrocyclic antiaromatic contributions (more negative t-SSE values) [2]. We will examine a new coronoid-related example that has these characteristics associated with antiaromaticity, which also represents a new type of concealed coronoid.

\section{A New Class of Concealed Diradical Coronoids}

A concealed diradical (or even-membered radical) benzenoid hydrocarbon is defined based on the peak-to-valley difference criterion by Gordon and Davison [12]. A peak-tovalley difference of zero for a non-Kekuléan benzenoid is called a concealed or hidden radical benzenoid system; this zero difference also occurs between the number of starred and unstarred carbon vertices. An example of a concealed diradical benzenoid is Clar's goblet $\left(\mathrm{C}_{38} \mathrm{H}_{18}\right)$ which can be constructed by joining two benzo[cd]pyrene monoradicals $\left(\mathrm{C}_{19} \mathrm{H}_{11}\right)$ at their unstarred peaks ( $c f$. with page 3517 in ref. $4)$; it has the same number of peaks as valleys but is a 


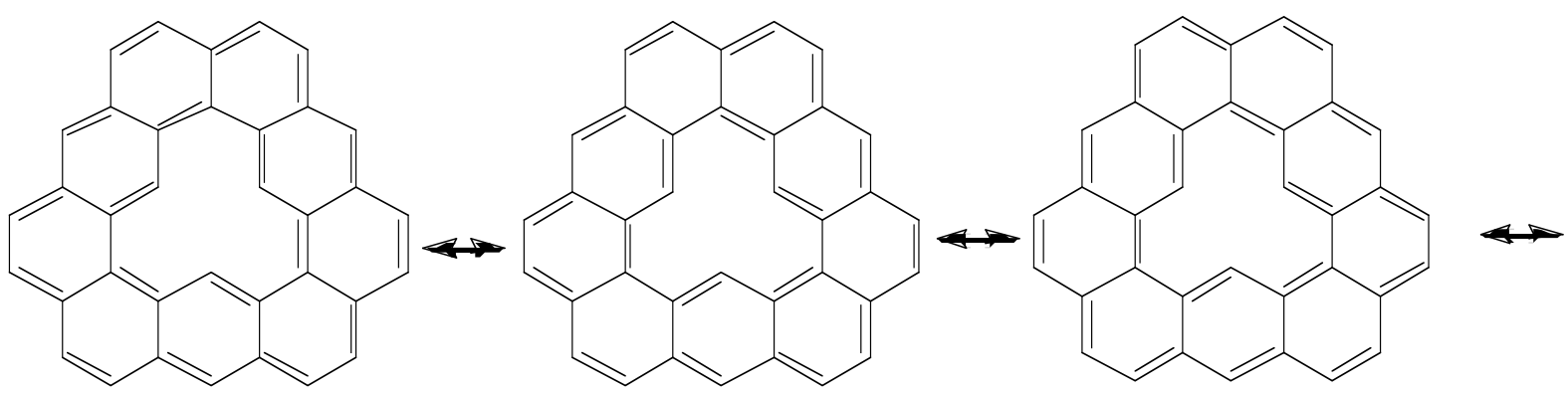

diradical. The search and study of concealed diradical benzenoid and coronoid hydrocarbons has been the subject of a number of papers [13]. Fig. (1) presents another type of concealed coronoid. This type of concealed diradical coronoid is an HMO diradical but a VB nonradical. The criterion for its recognition is based on McClelland's fragmentation principle [14]. Fig. (1) shows that the right-hand mirror fragment of this coronoid is an odd carbon monoradical and therefore by the pairing theorem the precursor coronoid must be doubly degenerate in the eigenvalues of zero and must be a concealed HMO diradical though it has a VB structure. This $\mathrm{C}_{44} \mathrm{H}_{20}$ coronoid is the smallest concealed HMO diradical. Using this right-hand mirror fragment, one can determine the unnormalized eigenvectors for the doubly degenerate zero eigenvalues of this coronoid given in Fig. (2). This same strategy was used to detect (even-membered carbon) diradical character of symmetrical indacenoids [15].

\section{Successive Circumscribing of Conjugated Polycyclic Hy- drocarbons with Hexagonal Rings}

We have shown that successive circumscribing with hexagonal rings leads to certain successors having certain characteristics. The characteristic patterns that emerge upon successive circumscribing various classes of polycyclic aromatic hydrocarbons are diagnostically useful. Successive circumscribing of benzenoids, fluorenoids/fluoranthenoids, and indacenoids leads to constant-isomer series [16]. Circumscribing of disjoint diradicals give nonradical successors whereas circumscribing nondisjoint diradicals leads to larger diradical successors; e.g., circumscribing the disjoint diradical of bisallyl $\left(\mathrm{C}_{6} \mathrm{H}_{8}\right)$ gives anthanthrene $\left(\mathrm{C}_{28} \mathrm{H}_{14}\right)$, a nonradi$\mathrm{cal}$, and circumscribing the nondisjoint diradical of triangulene $\left(\mathrm{C}_{22} \mathrm{H}_{12}\right)$ gives circumtriangulene diradical $\left(\mathrm{C}_{52} \mathrm{H}_{18}\right)$. Circumscribing a concealed diradical benzenoid will eventually lead to a nonradical benzenoid. For example, circumscribing Clar's goblet $\left(\mathrm{C}_{38} \mathrm{H}_{18}\right)$, a concealed diradical benzenoid, gives a Kekuléan $\mathrm{C}_{80} \mathrm{H}_{24}$ successor benzenoid. Successive circumscribing of a fluorenoid/fluoranthenoid hydrocarbon alternates from monoradical to nonradical species. Successive circumscribing of a concealed HMO diradical coronoid alternates from concealed HMO diradical to nonradical species. For example, circumscribing the $\mathrm{C}_{44} \mathrm{H}_{20}$ concealed HMO diradical coronoid in Fig. (1) gives a nonradical (Kekuléan) $\mathrm{C}_{84} \mathrm{H}_{26}$ coronoid and circumscribing again gives the $\mathrm{C}_{136} \mathrm{H}_{32}$ concealed HMO diradical shown in Fig. (3).

\section{Coalescence of Antiaromatic Holes in Graphene}

Fig. (4) shows the coalescence of two phenalenyl-shaped antiaromatic holes to form a pyrene-shaped aromatic hole. Using Benson's revised thermodynamic group additivity
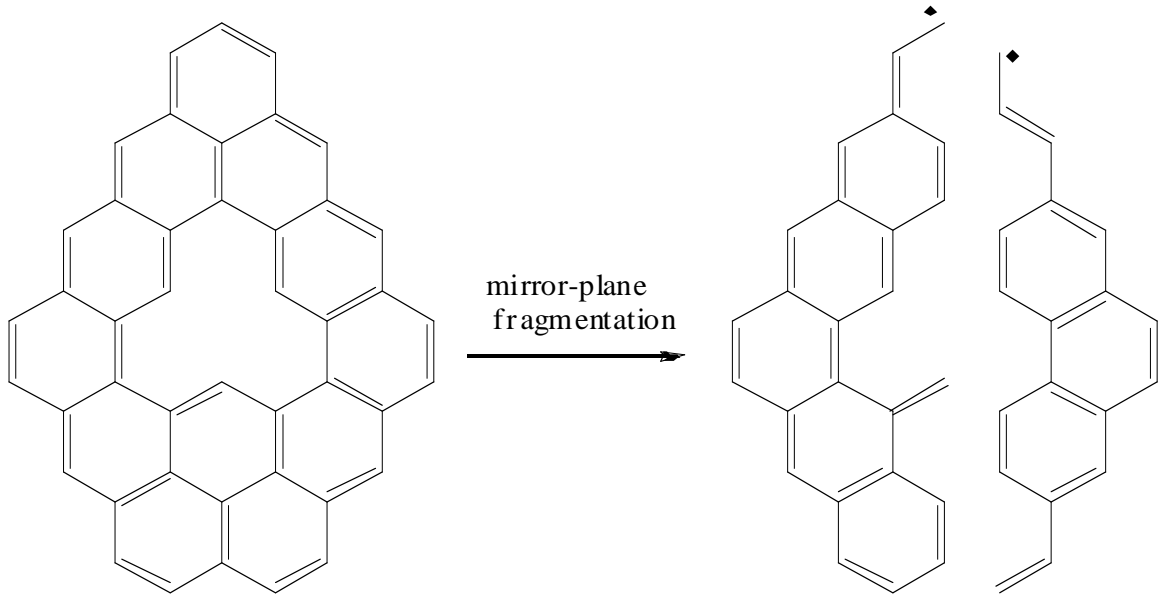

$$
\begin{aligned}
& \mathrm{C}_{44} \mathrm{H}_{20}, \boldsymbol{K}=54 \\
& E_{\pi}=64.1323
\end{aligned}
$$

$$
N_{\text {pc }}(\text { coronoid })=N_{\mathrm{H}}(\text { coronoid })
$$

$\begin{array}{cl}\begin{array}{ll}\text { left-f ragment } \\ \text { eigenvalues }\end{array} & \begin{array}{l}\text { right-fragment } \\ \text { eigenvalues }\end{array} \\ \pm 2.6824 & \pm 2.46473 \\ \pm 2.5672 & \pm 2.1183 \\ \pm 2.2441 & \pm 1.79001 \\ \pm 1.9461 & \pm 1.4753 \\ \pm 1.7902 & \pm 1.414214 \\ \pm 1.5998 & \pm 1.13501 \\ \pm 1.3963 & \pm 1.0 \\ \pm 1.2055 & \pm 0.64313 \\ \pm 1.1281 & \pm 0.59616 \\ \pm 1.0 & 0 \\ \pm 0.8803 & \\ \pm 0.3986 & \\ 0 & \end{array}$

Fig. (1). An example of a Kekuléan diradical coronoid hydrocarbon. Mirror-plane fragmentation gives a right-hand fragment which is an odd alternant hydrocarbon having a zero eigenvalue. This proves that the precursor $\mathrm{C}_{44} \mathrm{H}_{20}$ coronoid must ba a $\mathrm{HMO}$ diradical. 


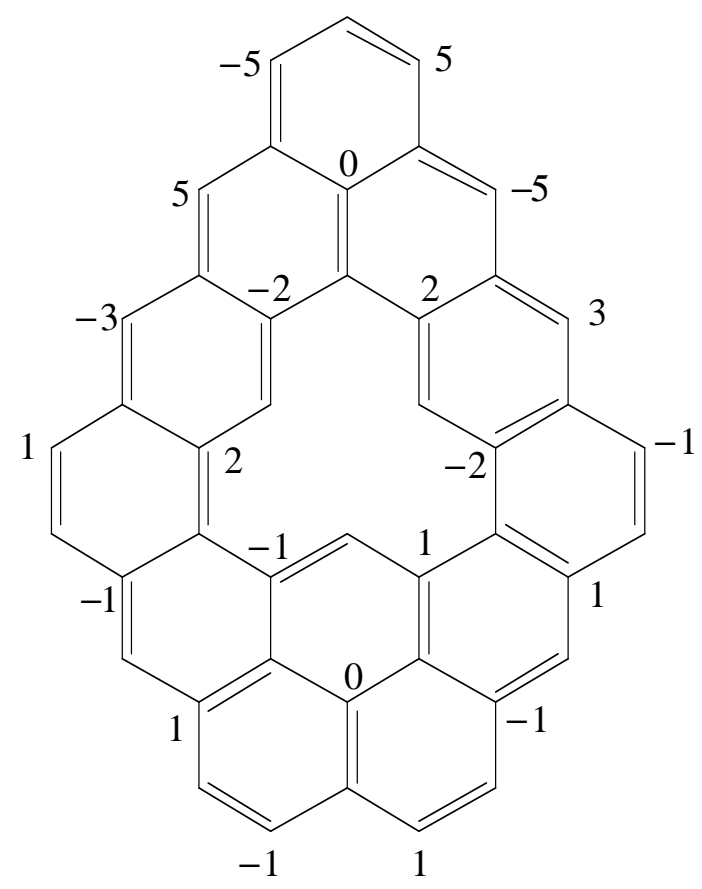

antisymme tric e ig envec tor

\section{$\mathrm{C}_{44} \mathrm{H}_{20}, \boldsymbol{K}=54$}

Fig. (2). Eigenvectors for the doubly degenerate zero eigenvalues. Interchange signs for other orthogonal eigenvector.

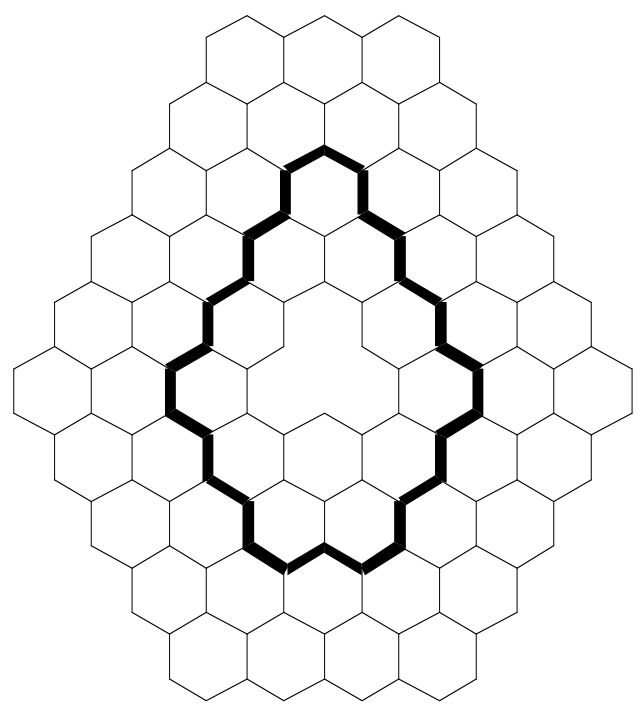

Circumscribing the $\mathrm{C}_{44} \mathrm{H}_{20}$ coronoid shown in bold twice give s the $\mathrm{C}_{136} \mathrm{H}_{32}$ coronoid shown, both of which are HMO diradicals and VB nonra dicals.

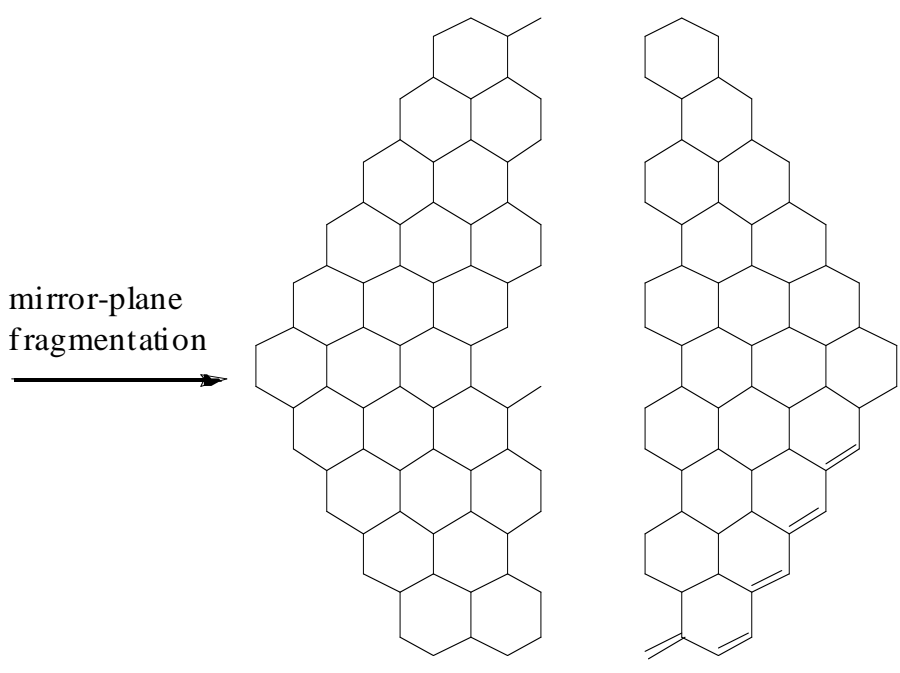

right-hand fragment is a $\mathrm{C}_{63}$ monoradical

Fig. (3). Circumscribing the $\mathrm{C}_{44} \mathrm{H}_{20} \mathrm{HMO}$ diradical in Fig. (1) twice gives a $\mathrm{C}_{136} \mathrm{H}_{32} \mathrm{HMO}$ diradical.

values [17], this process is estimated to have an $\Delta H($ coalescence $)=51.16 \mathrm{kcal} / \mathrm{mol}-97.16 \mathrm{kcal} / \mathrm{mol}=-46.7$ $\mathrm{kcal} / \mathrm{mol}$.

From the resonance-theoretic approach of Klein and coworkers [18], we note that if the antiaromatic holes have opposite spin polarization densities they are attracted toward each other and become canceled out in the successor aromatic hole (Fig. 4). Alternatively, if the antiaromatic holes have the same spin polarization densities they are repelled from each other. Thus the former should have a lower energy 


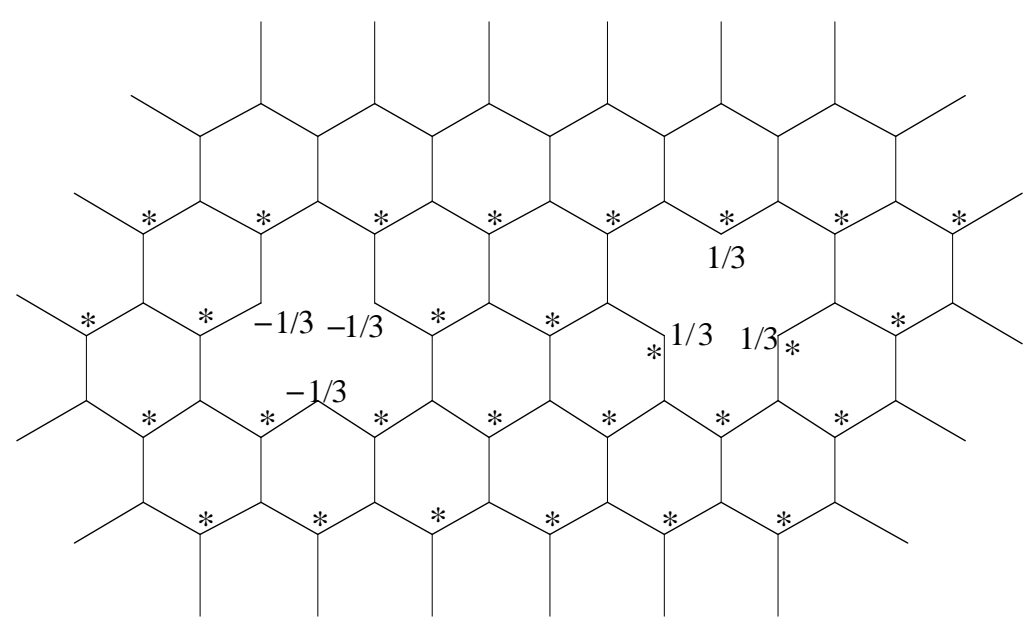

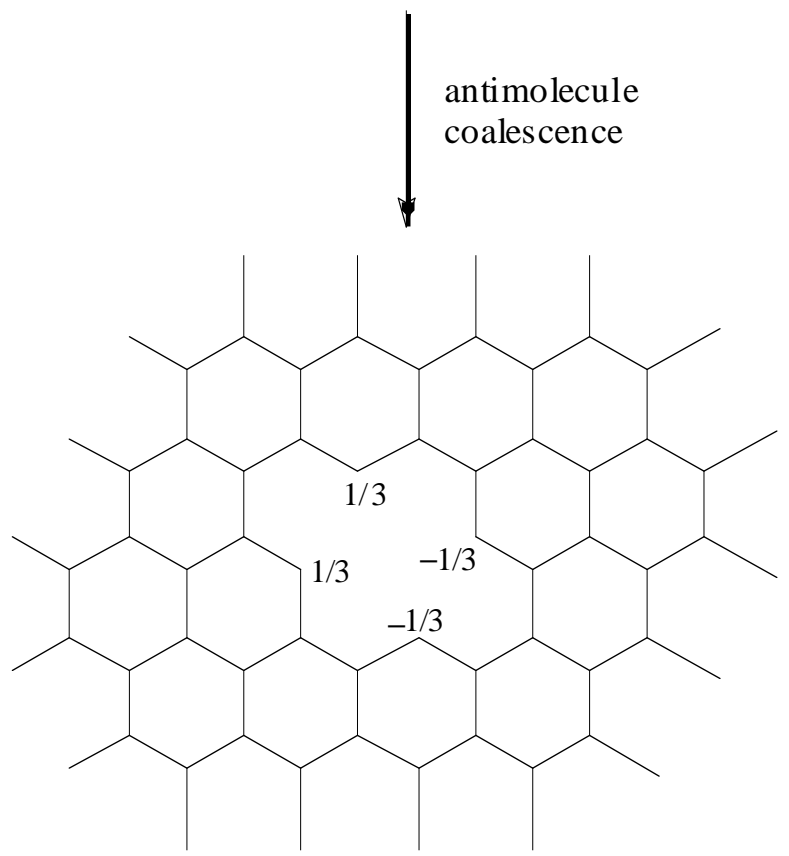

Fig. (4). Attraction and coalescence of oppositely spin polarized antiaromatic holes.

barrier than the latter though both have a thermodynamic propensity for to coalescence.

In the above mechanistic scenario, we have omitted details regarding whether the holes have dangling bonds or installed hydrogens. In the case of dangling bonds, we expect the three $\sigma$-orbitals with their electrons to be easily ionized to form a cationic cyclopropenyl aromatic-like hole. Under the influence of a magnetic field, one can visualize that the two electrons in this $\sigma$-aromatic hole and the twelve $\pi$-electrons in the antiaromatic rim should set up counter electron currents in analogy to the counter-rotating ring currents described by Fowler and coworkers [19]. With installed hydrogens, we expect the coalescence to reduce the associated steric hindrance interaction in the hole by concomitant extrusion of $\mathrm{H}_{2}$.

\section{CONCLUSION}

We have argued that circumcoronaphene $\left(\mathrm{C}_{72} \mathrm{H}_{24}\right)[2,20]$, the $\mathrm{C}_{44} \mathrm{H}_{20}$ coronoid in Fig. (1) and its dicircum $\mathrm{C}_{136} \mathrm{H}_{32}$ successor in Fig. (3) represent a new type of concealed (hidden) coronoid diradicals and have relatively more enhanced antiaromatic contributions because they are HMO diradicals though they have VB structures [2]. A model for one type of coalescence of antiaromatic holes in graphene has been suggested. The variables of antiaromaticity and spin polarization of Schottky defects need to be considered.

\section{CONFLICT OF INTEREST}

None.

\section{ACKNOWLEDGEMENT}

This work was supported in part by grants from the Office of the Vice Provost for Research (UMKC Research Incentive Fund Grant (K0710) and by the UM Board of Curators (K0906077).

\section{REFERENCES}

Brunvoll, J.; Cyvin, B.N.; Cyvin, S.J.; Gutman, I.; Tosić, R.; Kovaćević, M. Enumeration and classification of coronoid hydrocarbons. J. Molec. Struct. (Theochem), 1989, 184, 165-177. 
[2] Dias, J.R.; Aihara, J. Antiaromatic holes in graphene and related defects. Molec. Phys., 2009, 107, 71-80.

[3] Breslow, R. Antiaromaticity. Acc. Chem. Res., 1973, 6, 393-398.

[4] Randić, M. Aromaticity of polycyclic conjugated hydrocarbons. Chem. Rev., 2003, 103, 3449-3605.

[5] Aihara, J. Resonance energies of benzenoid hydrocarbons. J. Am. Chem. Soc., 1977, 99, 2048-2053.

[6] Hess, Jr., B.A.; Schaad, L.J. Hückel molecular orbital $\pi$ resonance energies. A new approach. J. Am. Chem. Soc., 1971, 93, 305-310; Schaad, L.J.; Hess, Jr., B.A. Hückel Molecular orbital $\pi$ resonance energies. The question of the $\sigma$ structure. J. Am. Chem. Soc., 1972, 94, 3068- 3074; Schaad, L.J.; Hess, Jr., B.A. Dewar resonance energy. Chem. Rev., 2001, 101, 1465-1477.

[7] Wannere, C.S.; Schleyer, P.v.R. How aromatic are large $(4 n+2) \pi$ annulenes? Org. Lett., 2003, 5, 865-868; Wannere, C.S.; Moran, D.; Allinger, N.L.; Hess, Jr., B.A.; Schaad, L.J.; Schleyer, P.v.R. On the stability of large [4n]annulenes. Org. Lett., 2003, 5, 29832986.

[8] Dias, J.R. Valence-bond and Hückel molecular orbital diradicals Alternant versus nonalternant effects. Aust. J. Chem., 2003, 56, 1225-1232.

[9] Aihara, J. A simple method for estimating the superaromatic stabilization energy of a super-ring molecule. J. Phys. Chem. A, 2008, $112,4382-4385$

[10] Wu, J.; Pisula, W.; Müllen, K. Graphenes as potential material for electronics. Chem. Rev., 2007, 107, 718-747.

[11] Dietz, F.; Tyutyukov, N.; Madjarova, G.; Müllen, K. Structure and energy spectra of polycyclic aromatic hydrocarbons with defects. $J$. Phys. Chem. B, 2000, 104, 1746-1761; Dietz, F.; Tyutyukov, N. Structure and properties of non-classical polymers. Chem. Phys. Lett., 1999, 246, 255-265; Tyutyukov, N.; Madjarova, G.; Dietz, F.; Müllen, K. Energy spectra of giant polycyclic aromatic hydrocarbons. J. Phys. Chem. B, 1998, 102, 10183-10189.

[12] Gordon, M.; Davison, W.H.T. Theory of resonance topology of fully aromatic hydrocarbons. J. Chem. Phys., 1952, 20, 428-435.

[13] Cyvin, S. J.; Brunvoll, J.; Cyvin, B. N. Search for concealed nonKekuléan benzenoids and coronoids. J. Chem. Inf. Comput. Sci., 1989, 29, 236-244; Cyvin, S. J.; Brunvoll, J.; Cyvin, B. N. The hunt for concealed non-Kekuléan polyhexes. J. Math. Chem., 1990, 4,
47-54; Guo, X.; Zhang, F.; Brunvoll, J.; Cyvin, B. N.; Cyvin, S. J. Concealed non-Kekuléan benzenoids. J. Chem. Inf. Comput. Sci., 1995, 35, 226-32; Dias, J.R.; Cash, G.C. Determining the number of resonance structures in concealed non-Kekulean benzenoid hydrocarbons. J. Chem. Inf. Comput. Sci., 2001, 41, 129-133; Cyvin, S. J.; Balaban, A.T. Struct. Chem., 1991, 2, 485-488.

[14] McClelland, B.J. Graphical method for factorizing secular determinants of Hückel molecular orbital theory. J. Chem. Soc. Faraday Trans. 2, 1974, 70, 1453-1456; McClelland, B.J. Eigenvalues of the topological matrix. splitting of graphs with symmetrical components and alternant graphs. J. Chem. Soc. Faraday Trans. $2 \mathbf{1 9 8 2}$ 78, 911-916; Dias, J.R. Molecular Orbital Calculations Using Chemical Graph Theory; Springer-Verlag: New York, 1993; p 2930.

[15] Dias, J.R. Indacenoid isomers of semibuckminsterfullerene. $J$. Chem. Inf. Comput. Sci., 1995, 35, 148-151.

[16] Dias, J.R. The polyhex/polypent topological paradigm: Regularities in the isomer numbers and topological properties of select subclasses of benzenoid hydrocarbons and related systems. Chem. Soc. Rev., 2010, 39, 1913-1924.

[17] Cohen, N.; Benson, S.W. Estimation of heats of formation. Chem. Rev., 1993, 93, 2419-2438.

[18] Ivanciuc, O.; Bytautas, L.; Klein, D.J. Mean-Field resonatingvalence-bond theory for unpaired $\pi$-electrons in benzenoid carbon species. J. Chem. Phys., 2002, 116, 4735-4748; Dias, J.R. Resonance-theoretic caculation of the ground state spin density of the $\mathrm{p} \pi$-system of edge atoms on graphene nanodots and nanoribbons. Chem. Phys. Lett., 2008, 467, 200-203.

[19] Steiner, E.; Fowler, P.W.; Jenneskens, L.W.; Acocella, A. Visualisation of counter-rotating ring currents in kekulene. Chem. Commun. 2001, 659-660; Steiner, E.; Fowler, P.W.; Jenneskens, L.W. Angew. Chem. Int. Ed., 2001, 40, 362-365; Monaco, G.; Fowler, P.W.; Lillington, M.; Zanasi, R. Designing paramagnetic circulenes. Angew. Chem., 2007, 119, 1921-1924.

[20] Dias, J.R. Structure and electronic characteristics of coronoid polycyclic aromatic hydrocarbons as potential models for Graphite layers with hole defects. J. Phys. Chem. A, 2008, 112, 12281-12292.

(C) Jerry Ray Dias; Licensee Bentham Open.

This is an open access article licensed under the terms of the Creative Commons Attribution Non-Commercial License (http://creativecommons.org/licenses/by-nc/3.0/) which permits unrestricted, non-commercial use, distribution and reproduction in any medium, provided the work is properly cited. 